\title{
Locus of control profile in anaesthetic nurse and theatre nurse students: A recruiting guideline?
}

Follow this and additional works at: https://www.journal.acorn.org.au/jpn

Part of the Health Services Administration Commons, Health Services Research Commons, Perioperative, Operating Room and Surgical Nursing Commons, and the Surgery Commons

(c) (i)

This work is licensed under a Creative Commons Attribution 4.0 License.

\section{Recommended Citation}

Meeusen, Vera; Mangnus, Carla; and Masters, Samantha (2017) "Locus of control profile in anaesthetic nurse and theatre nurse students: A recruiting guideline?," Journal of Perioperative Nursing: Vol. 30 : Iss. 3 , Article 1.

Available at: https://doi.org/10.26550/2209-1092.1016

https://www.journal.acorn.org.au/jpn/vol30/iss3/1

This Article is brought to you for free and open access by Journal of Perioperative Nursing. It has been accepted for inclusion in Journal of Perioperative Nursing by an authorized editor of Journal of Perioperative Nursing. 


\section{Authors}

Vera Meeusen

PhD, AFACHSM, MBA, RNA

Department of Perioperative Services, Peninsula Private Hospital, Redcliffe, Australia.

Carla Mangnus

MSC

Fontys University of Applied Sciences, Eindhoven, The Netherlands.

Samantha Masters

RN, BN

Clinical Educator, Peninsula Private Hospital, Redcliffe, Australia

\section{Locus of control profile in anaesthetic nurse and theatre nurse students: A recruiting guideline?}

\begin{abstract}
In the Netherlands, an individual with or without a nursing background can enrol in a nurse anaesthetist or theatre nurse program. Admission to the program requires either a secondary school diploma with a specialisation in physics and health, or a nursing degree. At the end of the study, the Dutch anaesthetic nurse is comparable to a nurse anaesthetist in other countries while theatre nurses are similar in scope of practice to scrub/scout nurses in other European countries. Retention of students is challenging, with an attrition rate of around 24 per cent adding to the cost for hospitals delivering the program ${ }^{1}$. Identifying ways to improve the efficiency of program delivery through enhanced student retention is a key priority for hospitals delivering this program. In this study, a longitudinal survey design was used to investigate student perceptions of their locus of control, a concept which is linked with motivation, persistence and achievement in study and work. Data was collected from a sample of 100 students over a five-year period in the Netherlands.
\end{abstract}

\section{Introduction}

Success of students depends primarily on factors such as language aptitude, motivation, anxiety and personality². In 1962, Rotter et al. developed the concept of 'locus of control' and a few years later published a validated internalexternal (I-E) scale for measuring this personality trait - the so-called Rotter's IE Control Scale ${ }^{3,4}$. Locus of control is a psychological social learning theory that refers to the extent to which individuals perceive control over their lives and their environment ${ }^{5}$. People assigning control of events to themselves are said to have an internal locus of control and are referred to as 'internals'. They believe that the outcome of their actions results from personal efforts, abilities, mood or permanent characteristics ${ }^{2.6}$. People who attribute control to outside factors are said to have an external locus of control and are termed 'externals'. Externals ascribe success and failure to factors such as luck, coincidence, fate, task difficulty, circumstances, teacher bias or the influence of others ${ }^{2,6}$.

In education, locus of control typically refers to how students perceive the causes of their academic success or failure in school ${ }^{2}$. The locus of control has a powerful effect on academic motivation, persistence and achievement throughout schooling. Internals assign their level of success to effort so are likely to work harder and are less affected by workload-induced stress ${ }^{7}$, whereas externals find working hard worthless because they assign success to external influences ${ }^{2}$. Internals prefer situations where control is possible ${ }^{8}$. When performance is poor, internals blame themselves, show a decrease in self-esteem and higher levels of anxiety than externals. Externals are less attracted to achievement-related tasks, as failure is more likely to be 
Table 1: Demographic characteristics

\begin{tabular}{|l|c|c|}
\hline \multicolumn{1}{l|}{} & Internal (N=19) & External (N = 72) \\
\hline theatre nurse / anaesthetic nurse & $9(47 \%) / 10(53 \%)$ & $38(53 \%) / 34(47 \%)$ \\
\hline female/male & $17(89 \%) / 2(11 \%)$ & $55(76 \%) / 17(24 \%)$ \\
\hline $\begin{array}{l}\text { previously obtained nursing degree / } \\
\text { no previously obtained nursing degree }\end{array}$ & $7(37 \%) / 12(63 \%)$ & $34(47 \%) / 38(53 \%)$ \\
\hline $\begin{array}{l}\text { previous relevant training / } \\
\text { no previous relevant training* }\end{array}$ & $5(26 \%) / 14(74 \%)$ & $21(29 \%) / 51(71 \%)$ \\
\hline $\begin{array}{l}\text { mean age of participants (SD) } \\
\text { number of students who dropped out of the course during } \\
\text { second or third year }\end{array}$ & $24.16(6.16)$ & $24.46(6.19)$ \\
\hline
\end{tabular}

*Diploma or degree obtained in a health care profession other than nursing but related to perioperative care.

attributed to the kind of task and luck $^{6}$.

Students with a belief in internal control are more likely to change their behaviour following positive or negative reinforcement than students with a belief in external control. This makes internals more proactive. However, behavioural change only occurs if the reinforcement is of any value for them. Externals seem to change behaviour easily, as they do not see it as a primary source for altering reinforcements ${ }^{6}$.

The goal of this study was to examine the relationship between the learning curve of anaesthetic nurse and theatre nurse students, and their locus of control personality. The learning curve was defined as the level of knowledge assessed by exams and progress tests and the time it took them to achieve sufficient knowledge. The result, a locus of control profile, can be used for recruiting and selecting potentially successful anaesthetic nurse and theatre nurse students, and gives teachers the opportunity to adjust their teaching to the needs of the student.

\section{Method}

\section{Sample and procedure}

Over a period of five years (2010-2015), this longitudinal survey study was performed among Dutch anaesthetic nurse and theatre nurse students. Firstly, in 2009 at Fontys University, Eindhoven, we studied a pilot group of anaesthetic nurse students only. After the pilot, students from both the theatre nurse course and the anaesthetic nurse course at the same university were studied. The study included three separate cohorts of anaesthetic nurse students and theatre nurse students each enrolled for a duration of three years. The study was approved as a quality assurance undertaking by Fontys University before data collection commenced.

Initially, all students were informed about the study and invited to participate. Students who agreed to participate were asked to fill in the locus of control test (LOC test) and demographic characteristics were collected (see Table 1). LOC test results and the demographic characteristics were collected by the secretary of the university. Individual participant responses were assigned a unique individual identifier and the anonymous data was analysed by the researchers. The LOC test was repeated every study year as a control measurement. Depending on their LOC test score students were classified as internals or externals. Students were informed they could withdraw from the study at any time.

\section{Measures}

Anaesthetic nurse (AN) and theatre nurse (TN) students were tested on all relevant competencies and knowledge across several domains of knowledge (as described below); however, testing was undertaken with each cohort to ensure role-specific content could be assessed.

The domains of knowledge were:

- Social interaction and cooperation: i.e. demonstrating behaviour in a deliberate and professional manner, whereby the intention of the action is clear to all parties.

- Care provision in an operating theatre complex: i.e. providing independent nursing care to individual care requirements for care recipients during the perioperative phase. 
- Professional skills: i.e. analysing, interpreting, evaluating and assessing the full range of care and justifying decisions.

- Organisation and professionalisation: i.e. establishing and coordinating actions that facilitate safe and proficient care.

- Technology: i.e. using technology, equipment, materials and tools to deliver safe and proficient care.

- Mentorship: i.e. supervising trainees or students in accordance with the curriculum.

- Teamwork: i.e. interacting with other professionals to deliver safe and proficient care.

Competency was assessed at five levels with increasing complexity and decreasing supervision, as follows:

- Level 1 is low complexity and direct supervision

- Level 2 is low complexity and indirect supervision

- Level 3 is moderate complexity and autonomous

- Level 4 is average complexity and autonomous

- Level 5 is high complexity and autonomous.

Students' overall knowledge was assessed every semester in a progress test. There were six tests, two in each year of the course. Each student needed to obtain a positive progress test result before they could proceed to the next study phase. Progress testing is a way to predict future competence and performance. It is based on subsequent equivalent yet different tests to determine the growth of functional knowledge for each student. This then enables more reliable and valid decision making about promotion to the next study phase and discourages 'binge' learning. It measures the student's improvement in relation to their syllabus. It is a rich source for continuous benchmarking and quality improvement ${ }^{9}$.

Students received two scores from their progress tests - one that indicated their level of knowledge and the other that indicated the time it took them to achieve sufficient knowledge. The knowledge scores were 1 (sufficient), 2 (more than sufficient) and 3 (good). A date was set for every progress test based on what was regarded as the 'standard' time: students who passed the test on this date scored 0 , students who were unsuccessful and needed to redo the test were defined as needing more time and scored 1 while students who successfully completed the test before the set date were defined as needing less time and scored -1 .

Progress tests also assessed students' level of competency and a student could obtain a positive result for more than one level at a time. For instance, a student deemed to be at competency level 3 would get a time score of 0 for level 2 and -1 for level three.

\section{Statistical analyses}

All data was collected in an Excel file and transported to SPSS for analysis. The independent variables (predictors) are demographics and study results. The dependent variable (outcome) is the locus of control profile. A chi-squared test was performed to determine if there were equal numbers of students with internal and external focus for each demographic characteristic. Then an independent T-test was used to determine any difference in study results between both LOC groups (SPSS 20.0 system, SPSS Inc, Chicago, Ill, USA). $P<0.05$ was considered statistically significant.

\section{Results}

Out of 104 students enrolled in the course over the study period, 100 individuals elected to participate (participation rate $=96$ per cent) . In total, ten students skipped a training year (accelerated study) and 26 students failed to complete the entire course. Of these 26 students, nine students dropped out during the first year of training. Their results were not included in the study because the data was too limited to analyse. Only students who dropped out in their second or third study year were included in the study. The study therefore included responses from 91 students - 19 internals and 72 externals and this data was analysed.

For each demographic characteristic there were equal numbers of students with internal and external focus (Table 1). Internal participants had a mean age of 24.16 years (SD = 6.16), while the mean age of externals was 24.46 years $(S D=6.19)$. We found no statistical difference between the progress test scores for knowledge or time of students with an internal focus and those with an external focus.

Because of the high incidence of dropout (in total 26 per cent), we checked for differences between students that completed the course and those who dropped out. An independent t-test was used to determine any differences in progress test scores for knowledge and time between students who completed the course and students who dropped out in the second or third study years (Tables 2a and 2b). There was a significant difference in the time taken to achieve sufficient knowledge for progress tests 1, 2, 5 and 6 . There was no significant difference in knowledge scores. 
Table 2a: Mean time scores for students who completed the course and received their diploma (Group 1) and students who stopped prematurely and didn't receive a diploma (Group 2)

\begin{tabular}{|c|c|c|c|c|c|c|c|c|}
\hline \multirow{3}{*}{$\begin{array}{l}\text { Progress } \\
\text { test } \\
\text { Test } 1\end{array}$} & \multicolumn{3}{|c|}{ Group 1} & \multicolumn{3}{|c|}{ Group 2} & & \\
\hline & $\mathrm{N}$ & M & SD & $\mathrm{N}$ & M & SD & \multicolumn{2}{|c|}{$t(d f)$} \\
\hline & 72 & -0.06 & 0.23 & 17 & -0.12 & 0.33 & t (880) & $=87^{\star \star \star}$ \\
\hline Test 2 & 72 & -0.11 & 0.33 & 17 & 0.35 & 0.86 & t (880) & $=87^{\star}$ \\
\hline Test 3 & 72 & -0.21 & 0.88 & 11 & 0.33 & 0.88 & $\mathrm{t}(635.82)$ & $=83$ \\
\hline Test 4 & 72 & -0.14 & 0.90 & 11 & 0.27 & 0.79 & t (739.01) & $=80$ \\
\hline Test 5 & 72 & -0.27 & 0.83 & 5 & 1.00 & 0.00 & t (671.68) & $=69.000^{* * *}$ \\
\hline Test 6 & 72 & -0.16 & 0.92 & 3 & 1.00 & 0.00 & t (880) & $=67.000^{* \star \star}$ \\
\hline
\end{tabular}

Time to achieve sufficient knowledge: less time (-1), standard (0), more time (1). Significant correlation at level ${ }^{*} p<0.05,{ }^{* *} p<0.01,{ }^{* *} p<0.001$.

Table 2b: Mean knowledge scores for students who completed the course and received their diploma (Group 1) and students who stopped prematurely and didn't receive a diploma (Group 2)

\begin{tabular}{|l|c|c|c|c|c|c|c|c|}
\multicolumn{1}{|c}{} & \multicolumn{9}{c|}{ Group 1 } & \multicolumn{3}{c|}{ Group 2 } \\
\begin{tabular}{|l|c|c|c|c|c|c|c|} 
Progress \\
test
\end{tabular} & $\mathrm{N}$ & $\mathrm{M}$ & SD & $\mathrm{N}$ & $\mathrm{M}$ & $\mathrm{SD}$ & $\mathrm{t}(\mathrm{df})$ \\
\hline Test 1 & 72 & 2.21 & .60 & 17 & 2.12 & .69 & $\mathrm{t}(.541)$ & $=87$ \\
\hline Test 2 & 72 & 1.97 & .65 & 17 & 1.82 & .64 & $\mathrm{t}(.852)$ & $=87$ \\
\hline Test 3 & 72 & 2.05 & .66 & 11 & 2.00 & .45 & $\mathrm{t}(.264)$ & $=82$ \\
\hline Test 4 & 72 & 1.92 & .65 & 11 & 1.90 & .88 & $\mathrm{t}(.068)$ & $=79$ \\
\hline Test 5 & 72 & 1.86 & .62 & 5 & 2.00 & .71 & $\mathrm{t}(-.497)$ & $=72$ \\
\hline Test 6 & 72 & 1.66 & .68 & 3 & 2.00 & 1.00 & $\mathrm{t}(-.826)$ & $=69$ \\
\hline
\end{tabular}

Level of knowledge: sufficient (1), more than sufficient (2), good (3).

\section{Discussion}

The goal of this study was to examine the relationship between the learning curve of anaesthetic nurse and theatre nurse students and their locus of control personality.

In this study, we did not find any statistically significant differences in progress test scores between students with an internal locus of control and those with an external locus of control. By contrast, a study by Gifford et al. encompassing 3066 college students indicated that students with an internal locus of control have higher grade point averages, while those with an external locus of control have lower grade point averages and higher risk of dropping out ${ }^{10}$. In our study, however, the dropout among internal students (39 per cent) was almost twice as high as among the external students (22 per cent). According to April $^{6}$, this may be associated with the high level of proactivity among internals and quitting was perceived as the best option. Our study showed that students who dropped out of the course took significantly longer to achieve sufficient knowledge for progress tests 1, 2, 5 and 6 than students who finished the course successfully. This evidence can be used to predict dropout in an early phase and should be an early warning sign for student, teacher and hospital facilitators.

According to Bedel ${ }^{11}$, in general, female students have significantly higher scores for locus of control which means they are more internally focused. In our study, we found that only 17 of 72 females (24 per cent) had an internal focus. Ghonsooly et al. ${ }^{2}$ studied the locus of control and learning results of students in three fields studying a general English course and found significant differences. Engineering students were significantly more internally focused than Science and Humanities students, and achieved higher results. Our finding was in line with this as 79 per cent of the nursing students were externally focused. Nursing, especially within operating theatres, can be regarded as a combination of science and humanities.

\section{Limitations}

This study had several limitations.

- We studied students from one educational institution only.

- We did not collect data determining the reasons for student attrition. Negative study results and other expectations from work and personal life changes may be reasons to dropout. 
- We were not able to assess the students during their clinical placements.

- The number of participants, especially the number of students with an internal locus of control was limited. However, the ratio of people with an internal locus of control to those with an external locus of control among the overall workforce is unknown and may or may not be reflective of the ratio reported in this study.

\section{Conclusions}

Locus of control had no influence on the learning curve of students, neither exam and progress test results nor time it took for students to complete the course. Importantly, a high level of student drop out (26 per cent) was seen during the course. Further study is necessary to determine why this attrition occurs and how to reduce it. The time taken for students to achieve sufficient knowledge at different stages of the course was a good indicator for the success rate in finishing the course. The data is insufficient to determine whether personality traits can be used to determine optimal student recruitment to perioperative programs of education.

\section{References}

1. Dijkstra B, Wiegmink H. Het beroepsprofiel van HBO-V studenten: leidt dit beeld tot uitval? Groningen: Hanzehogeschool Groningen; 2010.

2. Ghonsooly B, Elahi M. Validating Locus of Control questionnaire and examining its relation to general English achievement. JTLS 2010;1:117-143.

3. Rotter JB, Seeman M, Liverant S. Internal versus external control of reinforcement: a major variable in behaviour theory. In N. F. Washburne. Decisions, values \& groups (Vol 2). Oxford U.K: Pergamon Press; 1962.
4. Rotter JB. Generalized expectancies for internal versus external control of reinforcement. Psychol Monogr 1966;80:1-28.

5. Lefcourt HM. Locus of Control: current trends in theory and research. New York: Lawrence Erlbaum Associates Inc. Publishers; 1976.

6. April KA, Dharani B, Peters K. Impact of Locus of Control expectancy on level of well-being. J Eur Stud 2012;4(2):124-137.

7. Gray-Stanley J, Muramatsu N, Heller T, Hughes S, Johnson T, Ramirez-Valles J. Work stress and depression among direct support professionals: The role of work support and Locus of Control. JIDR 2010;54:749-761.

8. Spector PE. Behaviour in organizations as a function of employee's Locus of Control. Psychol Bull 1982;91:482-497.

9. Schuwirth LWT, Van Der Vleuten CPM. The use of progress testing. Perspect Med Educ 2012;1(1):24-30.

10. Gifford DD, Bricefho-Perriott J, Mianzo F. Locus of Control: Academic achievement and retention in a sample of university firstyear students. J Coll Adm 2006;191:18-25.

11. Bedel EF. An examination of Locus of Control, epistemological beliefs and metacognitive awareness in preservice early childhood teachers. ESTP 2012; special issue:3051-3060. 